\title{
Performing Economy Differently: Exploring Economic Personhood and Local
}

\section{Economic Diversity}

(in press for The Australian Journal of Anthropology Special Issue, August 2009)

Deirdre McKay

Department of Earth Sciences and Geography, Keele University, United Kingdom d.c.mckay@esci.keele.ac.uk

\begin{abstract}
:
Many popular conceptions of economy now delimit what counts as the 'real' economy by capitalist enterprises, market transactions and wage labour. Anthropologists describe such ideas of economy as abstract, dis-embedded (Polyani 1957a; 1957b) or virtual (Carrier and Miller 1998), arguing that these conceptions are not adequate to the empirical realities of lived experience. Beyond anthropology, there is a growing literature that theorizes the ways academic accounts have themselves brought a dis-embedded or virtual version of economy into being (Callon 2005; Callon and Caliskan 2005; Gibson-Graham 2006; Latour 2005; Mitchell 2002, 2008). Scholars advocating a performative approach argue academic notions of economy are not simply descriptive of empirical realities, but actively shape those realities, giving form to the ways that a 'real' economy emerges from particular socio-cultural fields. In the context of applied development anthropology, a performative reading of economy offers a helpful platform for applied research directed towards diversifying local economic understandings and practices. This paper explores the implications of performing economy differently through reflections on an action research project undertaken in the Philippines. Here, a performative approach recreated economy as a space of decision that demands active, ethical choices (Gibson-Graham 2006) and supported relational, rather than individuated, models of economic personhood.
\end{abstract}




\section{Introduction}

What counts as the 'real' economy? Over the last two decades, popular understandings of economy have tended to follow the lead of disciplinary economics, accepting the prevailing idea that capitalist enterprises, market transactions and wage labour delimit a 'real' economy. As aspects of economy, these forms of organisation, exchange, and labour are assumed to be universal and (relatively) easy to measure. Success in instituting these forms of economic organisation, as demonstrated by their measurement, has been considered to be the hallmark of development both for nation states and for local governments. Anthropologists, however, have long been critical of this popular consensus on economy and development, pointing out that it excludes from economic 'reality' many of the practices, institutions, and relations that sustain the majority of the world's inhabitants in their daily lives - the same practices, institutions and relations that are the objects of anthropological enquiry. Thus anthropological explorations of economy emphasise how, even where capitalist firms, formal markets and salaried jobs hold sway, people's lives continue to be shaped by gifts, reciprocal exchanges, and non-capitalist organisational forms. Anthropological research has shown that, even though people may fix their desire for development on standard, salaried jobs, they continue to sustain themselves, in part, with other forms of quotidian economic practice.

Building on the work of Karl Polyani (1957a, in Carrier 1998: 2), anthropology has theorised the dominant, popular accounts of economy as shaped by dis-embedding. With this term, Polyani named a process through which economic activities become increasingly represented as a singular realm, separable and separated from other relationships in which they are actually occurring. In disembedded accounts of economy, the broader socio-cultural field is not the context in which economic activities are considered. Instead, the 'real' is defined, in a very limited way, by the economic activities themselves. Polyani (1957b, and cited in Carrier 1998: 2) documented how dis-embedding happened both practically — in the ways people organise production, appropriation, 
distribution and consumption — and conceptually—in the ways that people represent these activities and their supporting institutions to themselves. Subsequent generations of scholars have taken Polyani’s concept of dis-embedding further. In his account of virtualism, James Carrier (1998: 2) ${ }^{l}$ argues that the abstract categories and actors which populate representations of the dis-embedded economy seduce people into believing it to be 'real', relying on naïve faith, rather than empirical evidence. Thus, true believers represent the world with concepts and models which they consider to describe fundamental economic reality. Not only does their fundamental reality underlie and shape the world, it is also a prescription for how the world ought to be. Thus believers exert practical efforts to ensure the world will conform to their vision of underlying structure. Theirs is a virtual reality — an economy seemingly real, but dependent on the conceptual apparatus and outlook that generate it. Their virtual reality obscures and distorts a 'real' reality which underpins it. Virtualism (Miller 1998: 197) characterizes the way economists operate and the economic categories which circulate in the rarefied realms of the World Bank, the International Monetary Fund, and the various national government agencies and international aid organisations which form the sociotechnical networks that design and implement development aid programs. Virtualism excludes from its representations of economy many of the objects of analysis and the development initiatives based on exchange relations and small-scale and communal production and distribution - typically engaged by anthropologists.

At the same time, accounts of economy as performative (see Callon 2005; Callon and Caliskan 2005; Gibson-Graham 2006; Latour 2005; Mitchell 2002; 2008) have originated in anthropology’s cognate disciplines - history, sociology, geography, and cultural studies. Theorising economy as brought into being by the performances of scholarship and allied activities has allowed this emerging community of scholars to move beyond what they consider to be the dead end of Polyani's theory of dis-embeddedness. Their performative theory of economy argues that

\footnotetext{
${ }^{1}$ A concept developed with Daniel Miller; see their 1998 co-edited volume, Virtualism.
} 
scholarship itself brings into being the particular version of economy it describes as the 'real' economy. Here, to be real simply means to be the object of a discourse. Economic historian Timothy Mitchell (2008: 453) rereads Polyani (1957b) to show that there is "no way to identify an economy independent of the forms of knowledge that might be involved in its constitution'. Instead, Mitchell (2008: 454, building on Callon 2005) theorises economics as having a performativity which brings economy into being by martialling 'complex but very common arrangements that connect together human agency, equipment or hardware of various kinds, and the codes or intellectual devices that enable networks and agencies of different sorts to operate'. Thus for Mitchell (2008: 463) the 'real' economy (that same realm which Carrier and Miller describe as virtual) emerges from 'techniques of business, patterns of empire, technologies of distribution, uses of money, control of energy, management of consumption, production of desire, styles of knowing and forms of expertise' characteristic of the late $20^{\text {th }}$ century. This economy comes into being as 'real' through 'a set of metrological projects' which, through their domination of politics, reformulate culture as 'an array of collective resources to be managed and a new set of fields for the government of conduct' (Mitchell 2008: 463). In this performative approach, all accounts of economy are 'real', but each comes into being through different sociotechnial networks

A performative approach challenges some established anthropological traditions. Anthropologists have long tried to show up the narrow conception of homo oeconomicus on which neoclassical economics relies as a fiction, attempting to replace this would-be universal subject with more complete, complex and varied accounts of human subjectivities and societies. Theorists of the performative economy note that anthropology's efforts to offer a 'truer' picture of an empirical reality have not had much success in overturning the march of neoclassical economic subjectivations. Instead, they advocate attempts to discover how scholars - including economists and other social scientists — are, in Mitchell's (2008: 455) words 'actively engaged in the coconstruction of socio-technical worlds that enable this narrow, calculating rationality to thrive'. 
This sets a particular challenge for anthropology: to discover not whether a particular account of culture or the subject is true or false, but how, where, in which spaces, and for how long a particular mode of knowing the subject can perform, enacting a reality which corresponds to its models (Callon 2005: 10).

In this essay, I recount the experiences of working with a performative notion of economy in a participatory action-research project conducted in the Philippines. ${ }^{2}$ With colleagues Katherine Gibson and Amanda Cahill, I am a member of an academic research group who applied this approach, seeking to shape understandings of economy through action, rather than adjudicating between contending claims about empirical realities. ${ }^{3}$ Thus, as an exercise in applied economic anthropology, our project tried to sidestep the near-exclusive focus on capitalism, capitalist enterprises and entrepreneurial subjects that dominated both development practice and academic critiques of development interventions in the Philippines. In a research partnership which included an international development donor, local governments, NGOs and community members, our project attempted to create a different understanding of economy by building on the existing diversity of local economic practices.

Most of our Philippine research partners - municipal government officials, NGO workers, interested community members - initially expressed the consensus view of the 'real' economy as constituted by capitalism, market and wages. However, they lived and worked in communities

\footnotetext{
${ }^{2}$ This action research was part of a larger project funded jointly by the Australian Research Council and Australia's official development assistance agency, AusAID (Australian Research Council Grant No. LP0347118 'Negotiating alternative economic strategies for regional development in Indonesia and the Philippines'. Katherine Gibson, Deirdre McKay and Amanda Cahill were responsible for the Philippines research activity and Kathryn Robinson, Andrew McWilliam and Jayne Curnow for the Indonesian component. In the context of recently decentralized governance, the four year research program tested out the utility of the Community Partnering model, an approach that was piloted as part of an action research project in the Latrobe Valley of Australia (Cameron and Gibson, 2001, 2005). Our partners in the Philippines were the Municipal Governments of Jagna, Bohol, and Linamon, Lanao del Norte, Unlad Kabayan, Bohol-Dev, AusAID, and community participants from Jagna and Linamon.

${ }^{3}$ This paper is based on a plenary session offered at the Australian Anthropological Society meetings held in Canberra in October of 2007. Unfortunately, Katherine Gibson and Amanda Cahill were unable to attend. Additional accounts from the Philippine side of the project have been published as Gibson-Graham (2005); McKay, Cahill, and Gibson (2007), and will appear in Cahill's forthcoming doctoral thesis (Cahill forthcoming 2009).
} 
where economic activities were predominantly non-capitalist, non-market, and unwaged. For these people, the 'real' economy had a geography; its potentials largely lay elsewhere, beyond the local and everyday experience, while they inhabited a mundane economy of lack. Our research thus began from a disjuncture in the ways people described economy. When we created an inventory of economic activities, our partners did not represent local economic practices of exchange, independent production and alternative markets as constituting a 'real' economy. Instead, many undertook self-conscious attempts to engage with 'business' and 'development' as abstract and rarefied spheres. Though, in participatory research activities, people described themselves to us as everyday economic actors in a context of kin relations, exchange relations and other social obligations, they felt inadequate. The central figure in the development model to which they aspired was the individual entrepreneur. Our project thus tried to help people see their mundane economy, and themselves, within it, in a different light. This essay recounts moments of resistance to the project's alternative approach, as well as some of its successes in creating community-based enterprises. In doing so, it suggests how different economic spaces within a community may be brought into being and describes contested constructions of economic personhood. ${ }^{4}$

\section{Contesting the 'real' economy}

An intense desire for access to the 'real' economy characterised our initial conversations with research partners in Jagna, a municipality of about 33,000 people on the south-eastern shore of Bohol, an island in the Philippines' Visayan archipelago. In Jagna, our research partners initially envisioned desirable futures through a lens coloured by prevailing accounts of economic development in the Philippines. ${ }^{5}$ Such futures often entailed 'playing on a global stage' by attracting foreign investment for export-oriented industrial development. Our partners sought development through large-scale, capitalist enterprises, employing individuals engaged in full-time,

\footnotetext{
${ }^{4}$ To make this argument, I draw on my own participant observations, interviews with group members, and accounts of project activities supplied by my colleagues, Katherine Gibson and Amanda Cahill. Direct quotes are taken from my fieldnotes (July and December 2005) or from transcripts of interviews conducted by Katherine Gibson in August 2007, as indicated.

${ }^{5}$ Cahill will expand on this in detail in her forthcoming doctoral thesis.
} 
salaried work, expressing a view of the economy as monological - shaped only by a capitalist logic. Their vision of development necessitated foreign investment, capital-intensive infrastructure, and a highly-skilled workforce. Living in Jagna (a comparatively small and remote municipality) this development vision required the patronage of powerful people from outside the municipality and the province. To this end, local officials petitioned donors and governments, built personal relationships between politicians and potential donors and investors, and presented the inhabitants of Jagna as patient and deserving citizens, people who complied with government policies and shared broader national development goals, but who largely lacked the individual resources, skills, and dispositions necessary for development.

Local visions for development were exemplified in discussions surrounding a proposal to create a large plantation of oil palms and a local oil processing facility geared to global exports. ${ }^{6}$ This proposed industrial plantation dominated public debate at the beginning of our project in 2003 . Politicians were keen to attract foreign donors to support this proposal, rather than seeking funds to support smaller enterprises that might engage a more local market. Caught up by the idea of 'producing for a global market', Bohol's leaders and their consociates selectively devalued aspects of their local lifeworld in favour of the rhetoric of economy promulgated by government agencies and the development aid community. Thus politicians, business leaders and NGO workers spoke to us of infrastructure and foreign investment—which Jagna lacked—rather than the potentials of local market exchanges and subsistence farming — which Jagna had in some abundance. Dreams of 'going global' allowed these people to participate in new systems of economic meaning — state policies, international regimes and global processes - that shape the Philippine national government's understandings of the economy. To materialise these global dreams, they needed to acquire further expertise in the language of aid and economics, generate statistics on local lack, and seek the patronage of higher-level government offices and politicians. Initially, some of our local

\footnotetext{
${ }^{6}$ Pers. comm. Amanda Cahill and Katherine Gibson, December 2003; see also Gibson-Graham (2005).
} 
partners wanted to direct our research towards influencing aid donors. They thus asked us to advise them on creating the right 'investment climate' for large-scale industry. In our partners' initial vision of the 'real' economy, 'business' and 'development' were spheres of action requiring sophisticated knowledges and complex performances of expertise. Not everyone could participate in materializing this economy; the poor and unskilled had to sit on the sidelines and wait.

Ordinary people, those outside the peer networks of elected officials and bureaucrats, watched development from a distance. Many of them had decided the best course of action was not to question or contradict the plans of the politicians, but to wait and see if the 'big time' projects would eventuate. Both the national media and local leadership told them that development required outside expertise, so people hesitated to take initiative in their daily lives. But their inaction was not acquiescence. Many people were critical of the premises that seemed to them to underpin megaproject development. Some were openly sceptical of the palm-oil proposal, concerned that the project would have adverse impacts on the sociotechnical networks that sustained their local lifeworlds. How, they wondered, would a mono-culture of non-native species grow in local soils? What would be the environmental and social effects? Would there really the strong and secure demand in the global market for palm oil that the plantation's proponents promised? Who would get the jobs? Some people predicted that it would be 'business-as-usual' if the plantation did go ahead, with most of the jobs going to clients of the provincial politicians and very little in the way of benefits trickling down to Jagna's underemployed 'stand-by' youth or part-time farmers. They foresaw that a monoculture plantation would merely continue to reproduce the monoeconomy from which they were excluded.

Our project's action research activities offered people a chance to instantiate a different vision of economy, one based on local diversity. Rather than performing a 'real' economy as arising from a monoculture of large, export oriented projects, our intervention was designed to facilitate diversity 
by performing the mundane economy as equally 'real.' We proposed to generate small-group, community-based enterprises, which would operate with existing skills and resources. Not everyone thought these activities worthwhile. One interested Jagna official responded to our ideas with, 'That's not going to get us into the WTO!' His comment reveals how desire for the 'real' economy is one for a world (economy) from which Jagna is excluded and of which Jagna's ordinary citizens can know very little. The 'real' economy of business and development as practiced in Jagna was thus both unworldly and unworlding. It existed elsewhere, but demanded to be made present in the local, through a set of measurements and complex technical exercises that would inscribe Jagna into the 'real' economic world from which it had been excluded. The desire for the global and technical underlying these notions of the 'real' economy occluded from view the possibility of enacting the economy as a rich and diverse realm of local expertise and innovation which sustained the community. Scott (1998: 311) calls this sphere métis (meaning the practical skills, know-how, experience, or knack) and it shapes local lifeworlds of sharing and exchange. By harnessing métis, we tried to expand and diversify a set of local economic activities that would share surplus across the community. Our community-based enterprises engaged métis to perform a different version of economy, on that contested the consensus view of the 'real' economy as delimited by salaried wages, formal markets and capitalist relations.

Local métis was a problem for the vision of large-scale capitalist development: if not an outright obstacle, it was inadequate to the trajectories of change people desired. In the kind of technical plans put forward by the proponents of the palm oil plantation, métis would hinder the materialisation of standard economic measurement. Thus the everyday knowledge of the 'common folk' was variously labelled 'backwardness', 'laziness', and a failure to be 'business-minded' and offered as evidence of a 'conservative mentality' that stood in the way of progress. People in leadership roles in government and NGOs wanted to engage instead with Scott's (1998: 319) techne - forms of generalisable knowledge and universal practice which are quantified, precise and 
verifiable - aimed at shaping economic outcomes. Our government and NGO collaborators thus believed in plans and reports as holding more predictive value than the much messier data gleaned from practical, daily experience. They were intent on measurements and accounts, rather than building relationships of exchange. Their attempts to materialize the 'real' economy required the performance of assessments, statistics, projections and comparisons with representations of largescale projects elsewhere. They assured Jagna's citizens that performing these technical exercises correctly was necessary to bring the 'real' economy into being. However, this outcome required the often intransigent 'common folk' to co-operate, yielding up the required data on the proper forms, accepting problematic simplifications and uncomfortable standardized categories. When people resisted these data-collection exercises, the 'mentality' of the ordinary citizens became a problem for would-be developers. Developers initiated workshops and training activities to organise the ordinary people of the community, improving their knowledge and attitudes, and to train them in various skills, while, at the same time, helping them to quantifying how they were 'lacking' and what things, skills, and dispositions they lacked.

\section{Negotiating knowledges: exercises in subjectivation}

Our project thus had to negotiate technical exercises designed to facilitate the emergence of the 'real' economy by installing particular modes of subjectivation. A key site of such negotiations was a training workshop in feasibility analysis held for our Jagna enterprise research team. Our NGO partner engaged a professional trainer - a graduate of the Master's of Business Administration program at Manila's prestigious Asian Institute of Management. This trainer was hired to help the research team master feasibility analysis, a skill that they would then transfer to groups of community participants who would, in turn, apply it to assess their own nascent business ideas. To some extent, this was what happened. However, responses to the training exercise threw into relief differences between the subjectivations of techne and the shape of the person who held Jagna's local métis. 
On the first day of the workshop the trainer offered lectures and a psychological test — the MyersBriggs inventory. He explained that the text would discover if the workshop participants had an individual 'entrepreneurial profile'. According to the trainer's presentation, not every individual had what it takes to be successful in business. His message was that because the market is the arena in which people test their individual value and abilities, and the market will find some individuals lacking, only particular types of people should go into business. This assertion was a compelling one, familiar to members of our project team, interpellating them into 'business' as individuated subjects. The Myers-Briggs revealed to them the dispositions of their individual selves by coding a series of preferences around ringing phones, and other daily activities drawn from the middle-class industrialised world. Our team leaders responded by asking the trainer if they should administer this or a similar standardized test to screen community members interested in participating in the enterprise research activities. Our research team understood that they were learning that it would not be sufficient for their would-be community participants to be motivated, to have relevant skills, resources or community connections. Instead, beyond interest and relationships, they anticipated that community participants would need to possess the right kind of - standardized, measurable individual dispositions to contribute to successful community enterprises. ${ }^{7}$ When confronted with this question, the trainer demurred: 'well, really, anyone could try business...' What the trainer and the research team were debating, in a very polite and somewhat muddled exchange, was the requirement that people to take on and enact a conception of the individuated person as the site of value to materialise the 'real' economy (see Graeber 2005: 450).

The individuated entrepreneurial subject may have been familiar to our research team, but the flowon effects from this mode of subjectivation proved to be problematic. On the second day, the trainer

\footnotetext{
${ }^{7}$ In the Philippines, people connect understandings of individuals and their business acumen to a wider discourse on 'Filipino values.' As distinct from the ethnic Chinese, Filipinos are supposed to attach greater value to interpersonal relations, redistribution and relative social position than to profits, making them unsuited to business.
} 
illustrated the concept of profit with a story about a trader who purchases fish below the prevailing market price and sells above it, pocketing the difference herself. One of the team members turned to me and said, only half joking, 'We understand profit. But where do we get the fish? ${ }^{8}$ The vision of the market offered by the trainer was one of a frictionless realm of open exchange, but the question of the fish immediately threw up frictions. 'Where to get fish' was not fundamentally expressing concern about declining fish stocks, but about other aspects of socio-technical networks that allow production, plunging us into tubs of fish, fresh from the sea, sitting on a dock or on board a boat. After all, one has to purchase fish under the prevailing price in order to make a profit (unless, of course, one owns or can rent the gear to fish). Alternatively, one could avoid using cash altogether. In Jagna, people who are not themselves fishers might access fish through traditional exchange practices. For example, if they are relatively poor, they might participate in hagpat (see Figure 1), a form of exchange in which they help fishers remove the catch from their nets in return for one-third of the fish. On the other hand, if they had some money to invest, they could establish a regular buyer-seller relationship with one or more fishermen, a practice called suki, to whom they would extend credit and good relations. However, they would still have to contend with market fees and compete or cooperate in relations with other traders. They might opt only to sell fish accessed through hagpat door-to-door, relying on the goodwill of neighbours and kin to make a profit. In Jagna, the question of sourcing fish isn't simply about an individual's access to the means of production; it is about how that access is vested in particular sets of social relations, networks of kinship, obligation and exchange. Such access is no abstract flow, but a highly socialised process shaped by local culture. Our research team thus knew that, while someone might buy fish from a fisher landing his catch at the wharf, it's unlikely she could get that fish at a price that would allow her to undercut his mother-in-law. Knowing this - that cheap fish will be hard to get for re-sale - is the métis of the mundane economy. But such mundane knowledge is excluded from the trainer's

\footnotetext{
${ }^{8}$ Noel Orias, pers. comm., July 2004.
} 
vision of an abstract market — that of the 'real' economy — and the kind of preparation his technical exercise can offer for launching a business.

Because it calls into being particular ways of performing these everyday social relations, the question of the fish is fundamentally a question about the kind of community in which people want to live. Do people want to be the kinds of individuated subjects who enact the standard model of economy put forward by the trainer? Or do they want to work from within local relations that they know? In the feasibility training workshop, the techne of individual enterprise planning obfuscated the ways in which everyday economic production was itself emergent from wider webs of social relations. The technical practices that shaped approaches to development in Jagna draw on the World Bank planning categories Carrier and Miller (1998) describe as the site of virtualism, whether this emerged through the desire to join the WTO, or the application of the Myers-Briggs' inventory in training. Yet there were alternatives present, too, in the diversity that makes up local economic métis and the modes of subjectivation that diversity offers. In Jagna, both the 'real' and the mundane economy come into existence through their performance, but each draws on very different sociotechnical networks and enacts different modes of subjectivation.

\section{Economic diversity and forms of personhood}

Our project used the diverse economy framework (Gibson-Graham 2006, Chapter 3) to help our research team and community members describe the social relations represented through their local economic practices, including forms of work sharing, reciprocity and (possibly obligatory) generosity (see Figure 1). This framework assisted our collaborators in seeing themselves as nodes within networks of community. By re-presenting existing diversity not as 'backwardness', but as a community asset with economic potentials, these discussions stimulated our partners into thinking about ways they could draw on traditional exchange relations, social practices, gifts etc. to support their ideas for small group businesses. Rather than advocating the reinvigoration of 'traditional' 
activities, we encouraged people to critically assess these practices as a basis for equitable and community-oriented economic innovation. Our community participants in the enterprise research groups agreed that many of their economic practices enacted an ethos of sharing and equity that was a vital and distinctive part of their culture. Few had thought about such forms and practices as having any potential for business, or considered how group businesses might activate the ethics of mutual support. They were curious, and sceptical, as to how they could use these ethics and practices as a starting point for community based social enterprises. Some enterprise research group members were also relieved; because this approach suggested they could get things started with the tools, skills and relationships they already had to hand—-their mundane economic métis.

[Figure 1 - Jagna's diverse economy]

Our discussions with the community participants suggested that the practices of sharing and exchange mapped within the diverse economy enact forms of economic personhood that are relational, rather than the individuated forms anticipated by the bureaucratic apparatus of development. In Jagna, the sociocultural field is constituted through particular relationships that extend through and beyond the boundaries created through subjectivation of persons as individuals. Thus, in their economic acts, persons more often than not represent a set of social relations - their household, their kin group, their barangay (neighbourhood cluster), their municipality, rather than simply just themselves. This is just as Strathern (1988: 161) argues in her theorisation of a relational subject: 'persons must enchain themselves in relation with others in order to appropriate and distribute, but also to produce'. Extending on Strathern, LiPuma (1998: 57) observes that persons in all cultures have individuated and relational aspects, with the challenge for anthropology being to identify where individual personhood comes to the fore and where people highlight the relational nature of sociality. Thus, our community participants could think of themselves as the kind of entrepreneurs described by the business-planning trainer: individual seller-subjects, 
unfettered by obligations to others. However, when considering how they might come to produce goods or services for sale, these same people chose to perform themselves as subjects emergent from the diverse webs of economic relations that make up the community, with their market being a dense network of affective and obligatory ties, exchange, gift, and redistributive relations. They were thus enthusiastic, despite some initial misgivings, about creating group, rather than individual, enterprises. When considering ideas for their potential enterprises, community participants quickly began enumerating not only their own contributions, but the skills and social networks of their kin and neighbours, the raw materials they could access through donations, and equipment they might borrow in order to experiment with various ideas. Of course, they were concerned that the same networks that made such things possible would also carry away the profits and place other demands on time and energy; they worried these same networks and relationships might actually be a liability to enterprise success. But the community participants also saw that group enterprises would be able to draw on a much wider range of resources and relationships and engage local markets through practices of reciprocal exchange, patronage, and charity. As groups, they could draw on an array of economic practices that would not be as accessible to individual producers.

To further explore how the relational economic person emerged within Jagna's diverse economy, I offer the example of one of our enterprise research groups. This group was composed of community participants who were small coconut farmers. Its thirteen members were part of a larger coconut farmers' federation who had decided they wanted to research the feasibility of making a value-added coconut product. They decided to try producing a local confectionary, nata de coco, made from fermented coconut juice. Nata is a commodity_-purchased in glass jars from supermarkets and local stores. Most nata comes into the Jagna area by truck, having travelled across the Bohol Sea from a factory in Cagayan de Oro, a city on the north coast of Mindanao, the island to the south. People use nata to make halo-halo - a cold, sweet snack sold for profit by selfemployed hawkers in the summer. And almost every household buys nata to prepare special sweet 
dishes offered to guests and exchanged with kin and neighbours during the municipal Fiesta, in mid-May, and the Christmas season. Local demand for nata is thus seasonal. Research in the local market — talking to store owners, neighbours, church associations — led the group to conclude that they could produce nata in response to local demand, peaking in the festive seasons, at a reasonable profit. The cost of shipping and trucking the nata, then holding it on store shelves until the holiday season was being passed onto local consumers. Thus, the market niche the nata group identified emerged because, as local producers, they could minimise these costs while selling a fresh product on a schedule timed closely to local demand.

The group organized production by drawing on traditional exchange relationships. By rotating tasks and putting a little bit of effort in at slack times in their agricultural work, the group 'evened out' the workload across the year. No member gave up their subsistence farming or their other ‘sidelines' - small, self-appropriating entrepreneurial activities. Instead, members relied on family and neighbours to substitute for them in production and marketing activities during busy times. One of the key group members, Jose, had worked in the nata factory in Cagayan de Oro. Jose had quit his job after finding that the salary could not meet his family's living expenses. He reminded the group of the importance of maintaining subsistence security and strong relations across the community to support both marketing and production. To produce nata, group members solicited donations of coconuts from kin, the others in their farmers group and local patrons. To market it, they elicited purchase orders for their proudly 'local, fresh product' from stores where they had outstanding accounts, from restaurants they patronized, and from the organisers of community social events. The group's first small production for sale, in the May Fiesta of 2005, was a success; they could not meet local demand and turned people away from their production site at the back of the NGO office. Despite setbacks, including vandalism of their fermentation room, they kept going throughout 2005 and 2006. As one member explained, 'we've seen that there's money to be made'. 
From the start, the group member was a relational economic person. After the vandalism incident, one person, Fely, put money into the groups' activities, not as a loan, but as a donation. Group members explained that, because Fely's children are grown-up and she has sizeable land holdings, 'she already has lots of rice'. This simple phrase encapsulates relational economic personhood. The assertion made about Fely's having rice is not claiming that Fely has a storehouse full of grain that is hers alone, or that Fely herself is taking on the form of rice, to be drawn down as a commodity stock by the group. Instead, this comment positions rice in the middle ground between commodity and exchange economies, gesturing down production chains and towards redistribution and reciprocity through dense personal networks. The rice that Fely 'has' depends on her ongoing access to lands held by her household, the relations of affection, kinship, and obligation that allow her to mobilise labour, and the redistribution of rice within and from her household. Knowing that all those relations are relatively stable and her family's subsistence is secured, Fely's input of her 'extra' cash allowed her to 'carry' the group. Fely's position in exchange relations, where her rice circulates in forms that mark and intensify her relations with others, underpins her ability to subsidise nata production. In turn, this activity builds up Fely's status and social networks, making her a 'bigger' person through the nata group — and, by extension, building the reputation of her household and kin group in the community. In this aspect, economic practice is not separable from what constitutes the person: Fely embodies her security in rice through her social networks and her actions within them.

Relations with others were also the site of investment when group members distributed their share of profits from the sale of their nata. While members put some of their earnings into the nata enterprise, they also took a proportion as wages. Most reported that they had spent these wages either on transport, 'special trips' - meaning visits to places that they could not normally afford, usually to follow up on papers for family members in government offices or seek medical care in the capital—or durable consumer goods, 'clothes for the children...something that will last'. These 
expenditures could be described as consumption, but they also represent redistribution - $\mathrm{a}$ reinvestment of profits into their relations with those who had helped to make or wanted to consume the nata de coco. Thus the distribution of profits can be seen to flow through the networks which constitute the economic personhood of the members of the group. When the group was asked if the money earned by group members had led to 'social jealousy", , our NGO team leader explained that people here are 'just too close to each other... and they do not think of getting jealous of others'. This comment, while probably not entirely true, further illustrates the local insistence on shared personhood. That closeness here does not refer to group boundariesdistinguishing jealousy among members as opposed to jealousy of members among non-member consociates - suggests how porous these boundaries actually are.

In August of 2007, the group was struggling with these boundaries of membership against the way in which development bureaucracy bounds personhood as individuated (cf. Trouillot 2001). Initially, the group had been operating with a structure specified by the regulations of the Philippine Department of Labour. This structure made the group eligible for government assistance and benefits, but stipulated one member per household. In the actual workings of the nata enterprise, however, the spouses of the members provided critical labour and resources. After some discussion, the group decided that they should be considered 'silent members', in recognition that they were just as involved in the success of the group as the 'full' members. Eventually, the group hoped to adopt another structural form and expand its membership, including more of the people - kin and neighbours - involved in its now considerable production and marketing chains — an expanded and expansive social field that indicates the inherent scope of relational economic personhood here. This field includes the other coconut farmers from whom they purchase coconuts at a discount, relatives who help by delivering orders to customers, children who take the place of their parents in

\footnotetext{
${ }^{9}$ A local Filipino English term, describing coveting someone's perceived economic success or positioning, as distinct from sexual jealousy.
} 
production activities etc. In the longer term, they hoped to be able to offer some casual work to jobless in the community.

Despite the challenges, group members found the process of starting their business very rewarding. They reported enjoying the sensual and social experience of producing nata, not merely the benefits of additional cash income, and the pleasures and challenges of working with the group within the community. They experienced good feelings when buying coconuts from farmers who previously had few, if any market outlets, as well as a swell of pride when showcasing their local product to visitors. When our NGO partners approached the local office of the Philippine Department of Science and Technology in the provincial capital, an officer travelled to Jagna to offer the group additional technical training and support in handling the nata culture. Recounting this, members expressed satisfaction that their efforts had attracted the respect and attention of government officials. Reflecting on the ongoing ups and downs of production and marketing, people reported they had developed creativity when confronted with problems, increased their work efficiency and built self-confidence in talking to others. They were most enthusiastic, however, when they spoke of the sensual pleasure of tasting the delicious nata-heretofore an expensive Fiesta treat - and the fun of producing red and green 'festive' colours, a novelty for many. These accounts of the group experience offer up the 'multiple layers - symbolic, temporal, sensory, through which subjectivities form' (Narotzky 2005: 83), and thus document the emergence of an alternative economic subjectivity that embraces and strengthens, rather than contradicts, relational economic personhood.

This account of the nata group shows how the economic actor-a person constituted through a dense network of social relationships, many either kin or customary — can draw on relationships and his or her social 'know how' to start a business. Such a possibility was mundane knowledge, part of the world of métis, and thus unremarked and unremarkable. Because this kind of social 
knowledge is continually pushed aside by the techne of development, it is not surprising that the group found licensing, registrations, the 'complying with' government programs that would allow them to access state support and expertise very difficult. The government attempts to treat people as individual actors, enrolled into hierarchical social structures, and demands membership lists, nominations of 'office bearers' and attempts to delimit the times, spaces and kinds of group activities. Government programs apply forms of technical organisation that attempted to enrol people in the service of broader state project of normalisation and the creation of a uniform field of rural progress intended to produce development. The end result, however, is all too frequently to obstruct local initiative and reinforce development dependency because the individuated model of the subject on which these technical exercises depended is not a location from which a great deal of métis can be mobilised. Despite these struggles in contesting the consensus version of economic 'reality', the Jagna enterprise groups shaped a development practice that mobilized local understandings of economic personhood as relational, rather than individualised, and to this they owed much of their tentative success. ${ }^{10}$

\section{Conclusion}

Our project allowed people to draw on the diversity of local economic practices and perform economy differently. Because it opened up a space in which relational economic personhood could be recognized as an asset, rather than a liability, the project process revealed new opportunities for social enterprise. This was an innovation in a context where conventional development engagements with the 'real' actually cause métis to vanish from view before desire for the imagined outcomes, individual beneficiaries and calculable benefits of the global economy, locally perceived. Here, the suggestion that group initiatives which facilitate relational forms of personhood could mobilize métis towards success offered a glimmer of hope. The community enterprise form is also

\footnotetext{
${ }^{10}$ As of 2008, the group has suspended production, due to struggles with a geographically dispersed membership, a lack of money to support the increasing costs of transport to meetings and production events, and the absence of a leading figure to coordinate activities. However, the group is seeking funds for a new processing site and has expressed motivation to resume their activities (see Community Economies Collective and Katherine Gibson, forthcoming, 2009).
} 
locally appropriate, positing an enterprise as itself relational—a node or pivot point among many points in the economic ebb and flow of the locality. Thus, as a development model, the relational enterprise complements both a renewed focus on household livelihoods as comprised of portfolios of occupations and a broader set of strategies which advocate creating niche markets for social enterprise production, where products made with a local ethic do not compete on the same terrain as commercial products.

Returning to the performative approach to economy, in their experiments with these enterprise groups, people discovered that they did not need to choose to perform themselves as more individuated kinds of subjects to experience success in business. Instead, they could choose to reenvision their mundane economy in a new light. Our approach performed an economy in which both local métis and relational forms of personhood were considered as potentials, allowing people to mobilise local economic diversity in creative ways. This approach does not necessarily exclude individual enterprise and technical economic exercises, but positions them within a much broader range of subjects and actions. By diversifying the possible versions of economy that can become 'real' for local people, this performative approach offers an alternative economic subjectivity, so that people no longer find themselves 'lacking' individuals, stuck, noses pressed to the window, waiting for development.

\section{Acknowledgements}

My thanks to Katherine Gibson and Amanda Cahill for field data, references and extensive comments on this draft; to the people of Jagna, Bohol and our research team there for being generous hosts and sharing their experiences with us; to Sandra Davenport at ANU for editing and formatting. The usual caveats apply. 


\section{References}

Cahill, A. 2009. New partnerships for development: exploring alternative economic spaces for community. Unpublished Ph.D. thesis, Department of Human Geography, Research School of Pacific and Asian Studies, The Australian National University, forthcoming.

Callon, M. and K. Caliskan, 2005. New and old directions in the anthropology of markets. Paper presented at the Wenner-Gren Foundation for Anthropological Research Conference, New Directions in the Anthropology of Markets, New York University, 5 April.

Callon, M. 2005. Why virtualism paves the way to political impotence: a reply to Daniel Miller's critique of The Laws of the Markets. Economic Sociology, 6(2): 3-20.

Cameron, J. and K. Gibson, 2001. Shifting Focus: Pathways to Community and Economic Development, A Resource Kit, Latrobe City and Monash University. http://www.communityeconomies.org/action/actionSF1.pdf

Cameron, J. and K. Gibson, 2005. Alternative pathways to community and economic development: The Latrobe Valley Community Partnering Project. Geographical Research 43(3): 274-285.

Carrier, J. 1998. Introduction. In J. Carrier and D. Miller (eds) Virtualism: a New Political Economy, pp. 1-24. Oxford: Berg.

Carrier, J. and D. Miller, 1998. Virtualism: a New Political Economy. Oxford: Berg. Community Economies Collective and Katherine Gibson, 2009. Building community-based social enterprises in the Philippines: diverse development pathways. In Amin, A. (ed.) Plural Economy, Plural Provision: The Social Economy in International Perspective. London: Zed Books, in press.

Gibson-Graham, J.K. 2005. Surplus possibilities: postdevelopment and community economies. Singapore Journal of Tropical Geography 26(1): 4-26.

Gibson-Graham, J.K. 2006. A Postcapitalist Politics. Minneapolis: University of Minnesota Press. Graeber, D. 2005. Value: anthropological theories of value. In J. Carrier (ed.) A Handbook of Economic Anthropology, pp. 439-455. Cheltenham, UK: Edward Elgar. 
Latour, B. 2005. Reassembling the Social. An Introduction to Actor-Network-Theory.

Oxford: Oxford University Press.

LiPuma, E. 1998. Modernity and forms of personhood in Melanesia. In A. Strathern and M.

Lambek (eds) Bodies and Persons: Comparative Perspectives from Africa and Melanesia, pp. 53-80. Cambridge: Cambridge University Press.

McKay, D. Cahill, A. and K. Gibson. 2007. Strengthening community economies: strategies for decreasing dependence and stimulating local development. Development Bulletin 72: 60-65.

Miller, D. 1998. Conclusion: A theory of virtualism. In J. Carrier and D. Miller (eds) Virtualism: a New Political Economy, pp. 187-215. Oxford: Berg.

Mitchell, T. 2002. Rule of Experts: Egypt, Techno-Politics, Modernity. Berkeley: University of California Press.

Mitchell, T. 2008. Culture and economy. In T. Bennett and J. Frow (eds) The Sage Handbook of Cultural Analysis, pp. 447-466. London: Sage.

Polyani, K. 1957a. Aristotle discovers the economy. In K. Polyani, C. Arensberg, and H. Parson (eds) Trade and the Market in the Early Empires: Economies in History and Theory, pp. 64-94. Glencoe, Ill: The Free Press.

Polyani, K. 1957b. The economy as instituted process. In K. Polyani, C. Arensberg, and H. Parson (eds) Trade and the Market in the Early Empires: Economies in History and Theory, pp. 243270. Glencoe, Ill: The Free Press.

Narotzky, S. 2005. Provisioning. In J. Carrier (ed.) A Handbook of Economic Anthropology, pp. 7893. Cheltenham, UK: Edward Elgar.

Scott, J. 1998. Seeing Like a State: How Certain Schemes to Improve the Human Condition Have Failed. New York: Yale University Press.

Strathern, M. 1988. The Gender of the Gift: Problems with Women and Problems with Society in Melanesia. Berkeley: University of California Press. 
Trouillot, M-R. 2001. The anthropology of the state in an age of globalization: close encounters of the deceptive kind. Current Anthropology 42(1): 125-138. 
Jagna's Diverse Economy

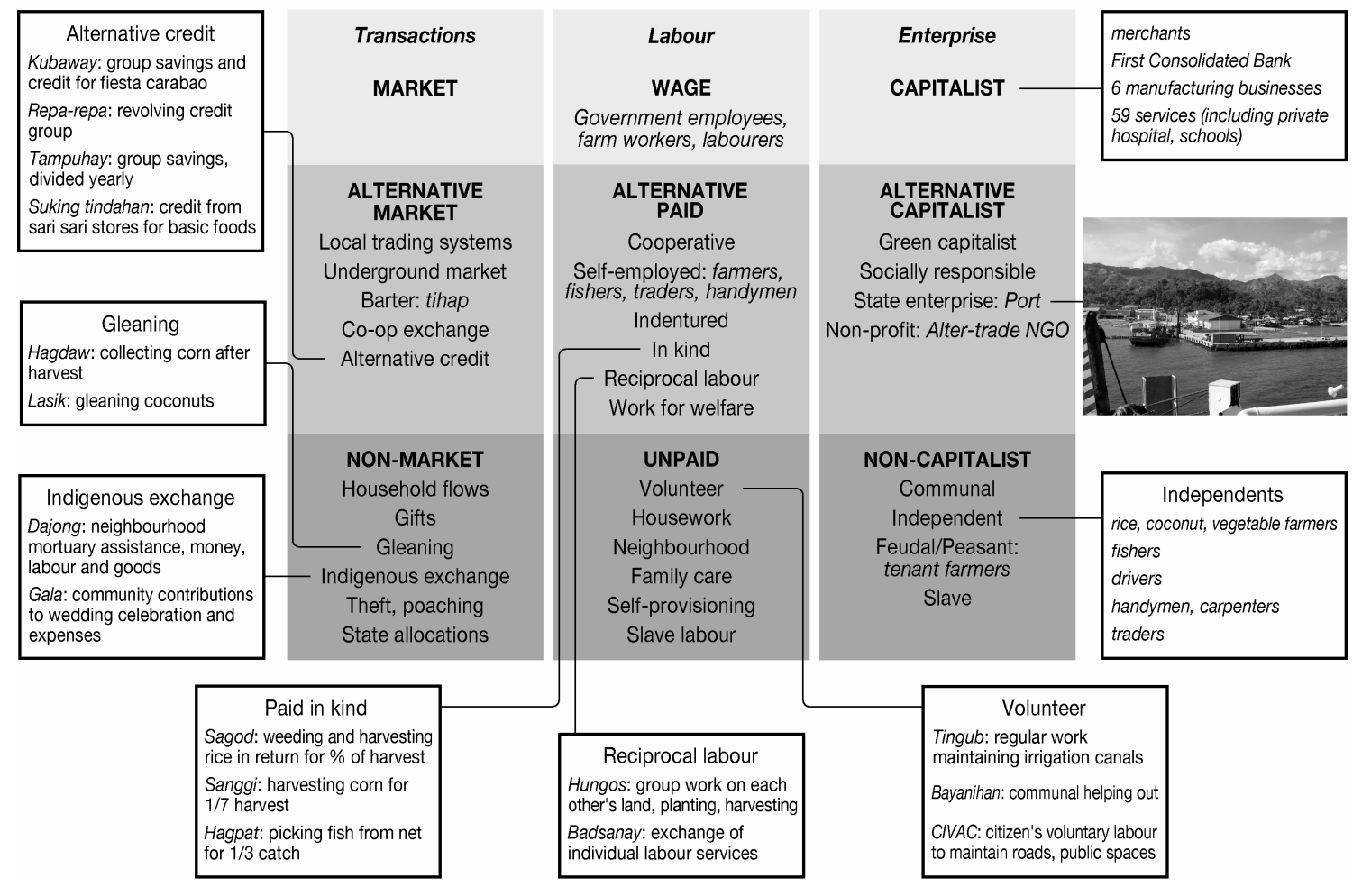

